\title{
The Use of Forensic Entomology in Legal Veterinary Medicine: A Case Study in the North of Italy
}

\author{
Defilippo $\mathrm{F}^{*}$, Rubini $\mathrm{S}^{2}$, Dottori $\mathrm{M}^{1}$ and Bonilauri $\mathrm{P}^{1}$ \\ ${ }^{1}$ Zooprofilattico Institute of Lombardy and Emilia-Romagna (sez. Reggio Emilia) Via Pitagora, 242100 Reggio \\ Emilia, Italy \\ ${ }^{2}$ Zooprofilattico Institute of Lombardy and Emilia-Romagna (sez. Ferrara) Via Modena 483, 44044 Cassana - \\ Ferrara, Italy
}

${ }^{*}$ Corresponding author: Defilippo F, Zooprofilattico Institute of Lombardy and Emilia-Romagna (sez. Reggio Emilia) Via Pitagora, 242100 Reggio Emilia, Italy, E-mail: francesco.defilippo@izsler.it

Citation: Defilippo F, Rubini S, Dottori M, Bonilauri P (2016) The Use of Forensic Entomology in Legal Veterinary Medicine: A Case Study in the North of Italy. J Forensic Sci Criminol 4(1): 101. doi: 10.15744/23489804.4.101

\section{Received Date: October 15, 2015 Accepted Date: February 24, 2016 Published Date: February 25, 2016}

\begin{abstract}
During winter 2010 a forensic entomological study was undertaken in San Bartolomeo in Bosco (FE) Emilia-Romagna Region (North of Italy) on different animal carrion found in a farm several days after they died.

The entomological evidence collected at the scene consisted of Calliphoridae (larvae of Calliphora vicina), Stratiomydae (larvae of Hermetia illucens), Dermestidae (larval exuviae of Dermestes maculatus). During diagnostic investigation the Diptera Larvae were taken from the carrion and were reared in the laboratory under constant temperature, humidity and fotoperiod. The minimum Post Mortem Interval (mPMI) was calculated using the quantity of thermal energy necessary for a given species to complete its life cycle from eggs to imago (accumulated degree-days-method). The results of the calculations were consistent with what the judicial investigation later showed. This case report illustrated the importance of using insects in legal veterinary medicine for define the time and circumstances of the death of an animal.
\end{abstract}

Keywords: Calliphora vicina; Forensic entomology; Legal veterinary medicine

\section{Introduction}

Forensic entomology is based on the identification of necrophagous insects and the study of their biology. It is a useful tool to estimate scientifically the time elapsed since death. The use in legal veterinary medicine has been limited but appears to be gaining momentum. The information currently available in the literature from human death or abuse investigation is applicable to the veterinary arena. Indeed inside entomological laboratory from less a decade work professionals with proper preparation in the field of forensic entomology aimed at assist the vets in forensic investigations. In this scenario the forensic entomologist is called for interpret the post-mortem signs that help to clarify possible abuse/neglect of pets (i.e. myiasis and canthariasis) or/ and define the Post Mortem Interval (PMI) of an animal. For this reason the insects are evidence. Forensic entomology is a very useful method of determing elapsed time sice death after $72 \mathrm{hrs}$. It is accurate a day or less, or a range of days, and may be the only method available to determine elapsed time since death. Determining time of death is extremely important in a death investigation as it focuses the investigation into the correct time frame. This can support or refute a suspect's alibi and improves the efficiency of the criminal investigation. Traditionally, times of death determinations are made for human homicide victims. However, forensic entomology can be equally applicable when the victim is not human, but an illegally killed wild animal. The ages of insect immature stages found on a dead body can provide evidence for the estimation of a minimum PMI ranging from 1 day up to more than 1 month, depending on the insect species involved and the climatic conditions at the death scene [1]. Blowflies are typically the first colonizers, attracted to the carrion by the odor produced during decomposition [2-4]. Because the rate of development of immature stages is a function of the ambient temperature and/or the temperature of the maggot mass present on carrion, the age of specimens is positively correlated with the summed thermal input they accumulate during growth [5,6]. The standard technique used to estimate the rate of development of insects over a period of time with temperature compensation is termed accumulated degree hours $(\mathrm{ADH})$ or accumulated degree days $(\mathrm{ADD})$, which are a summation of temperature $\left({ }^{\circ} \mathrm{C}\right)$ above the lower development threshold (LDT) multiplied by time (hours or days). The LDT is the temperature value below which insect development stops, It is most commonly estimated by measuring developmental rates at a range of temperatures and fitting a regression line to the results. This can then be extrapolated to the $\mathrm{x}$-axis where development is zero. It is species specific [7]. 
This method is clearly inaccurate for insects that start breeding late in decomposition (like coleopterans); but the use of arthropod succession patterns can enable the use of data concerning these insects [8]. Indeed arthropods progress through a natural succession pattern on animal remain. Samples of the arthropod community from remain could provide estimates of where the remains are in the succession process and thus represent a minimum postmortem interval. This ecological process has been well documented for decomposing animal remains [9]. In the present case, several carrion of animals (Sheep, Goat, Pot-bellied Pig, Emu and dog), at different decomposition stages, were collected in a farm. Entomological evidence was abundant and present on each carcass. The PMI was estimated on Calliphora vicina, Hermetia illucens and Dermestes maculatus samples as discussed in the result section.

\section{Materials and Methods}

On February 28, 2010 several carrion and bones of Sheep (Ovis aries) (Figure 1), Goat (Capra hircus) Pot-bellied Pig (Sus scrofa) (Figure 2), Emu (Dromaius novaehollandiae) (Figure 3) and dog (Canis lupus familiaris) (Figure 4), were collected by veterinarian of Local Official Veterinary Service of Ferrara in farm located in San Bartolomeo in Bosco (FE) (North of Italy) and sent to Istituto Zooprofilattico Sperimentale of Lombardia and Emilia Romagna (IZSLER) for diagnostic investigations. During the necropsy executed on March 02, different insects (larval and adult stage) were collected to determine the time of death.

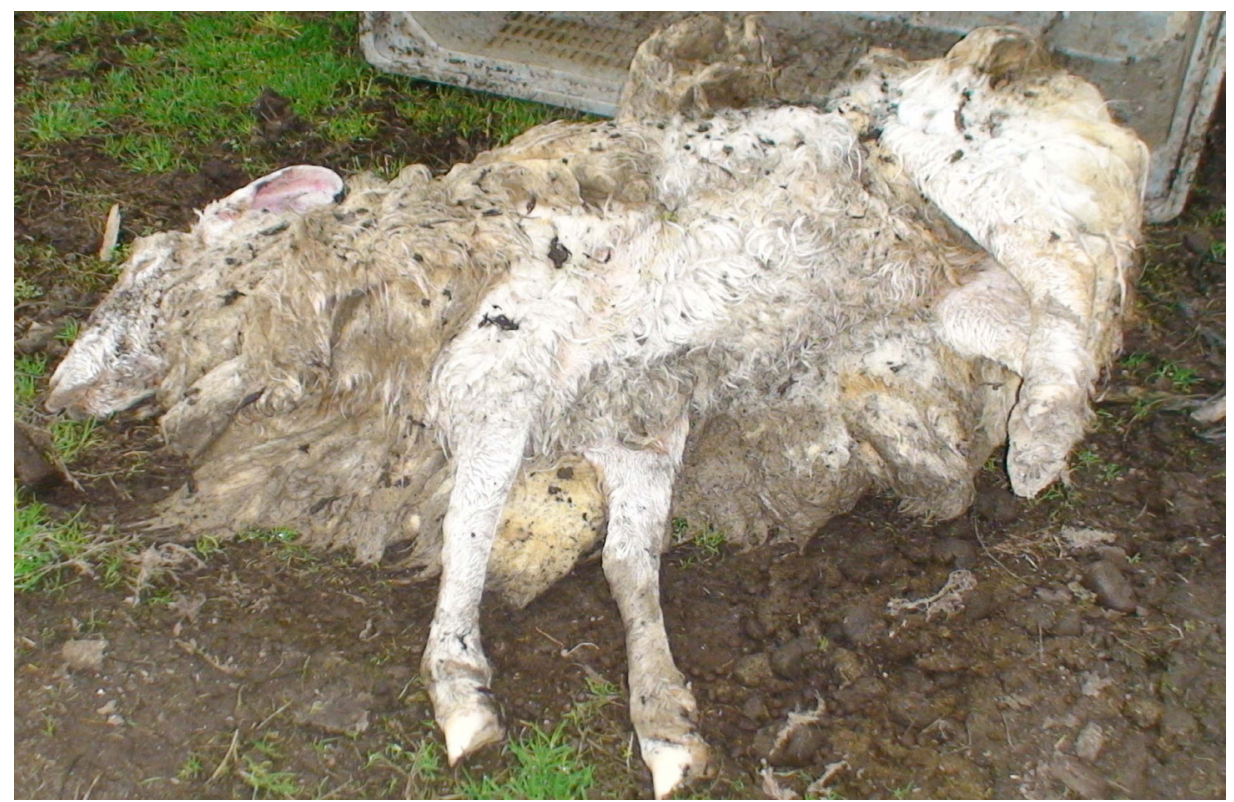

Figure 1: Sheep carrion

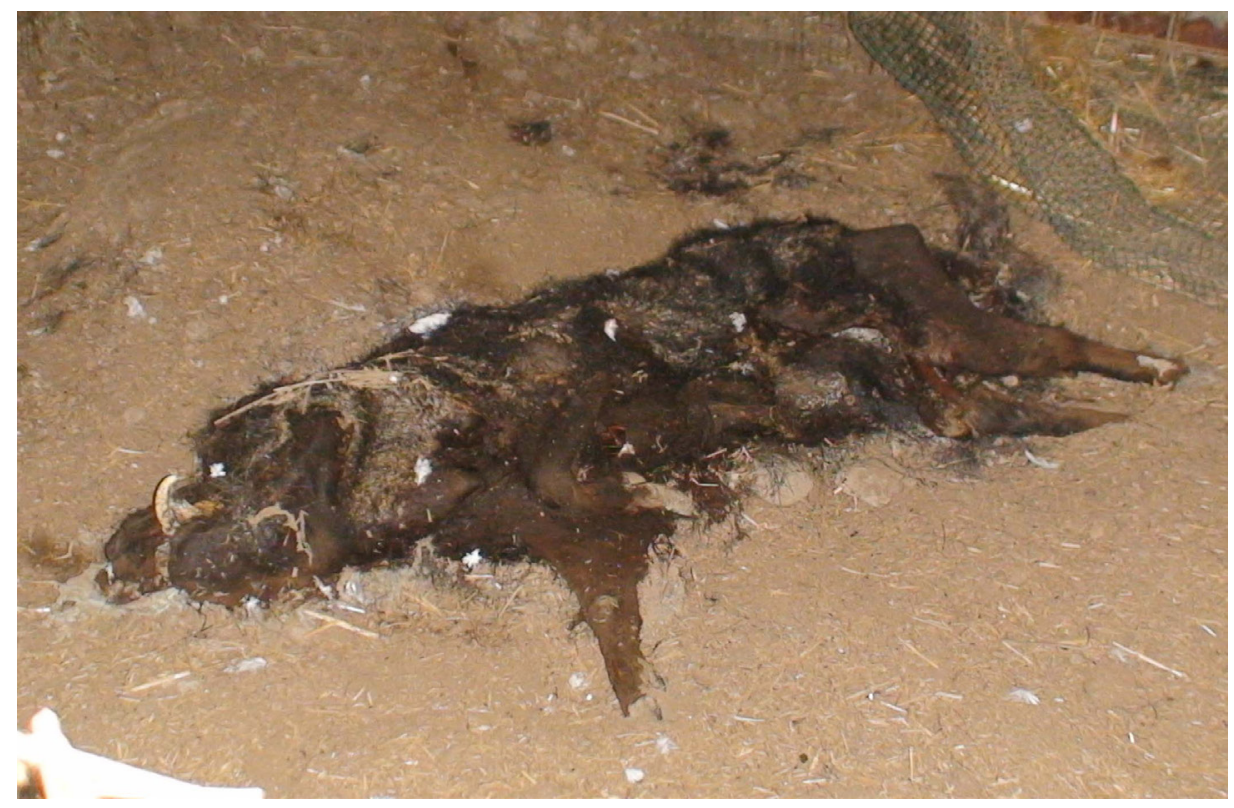

Figure 2: carrion of Pot-bellied Pig 


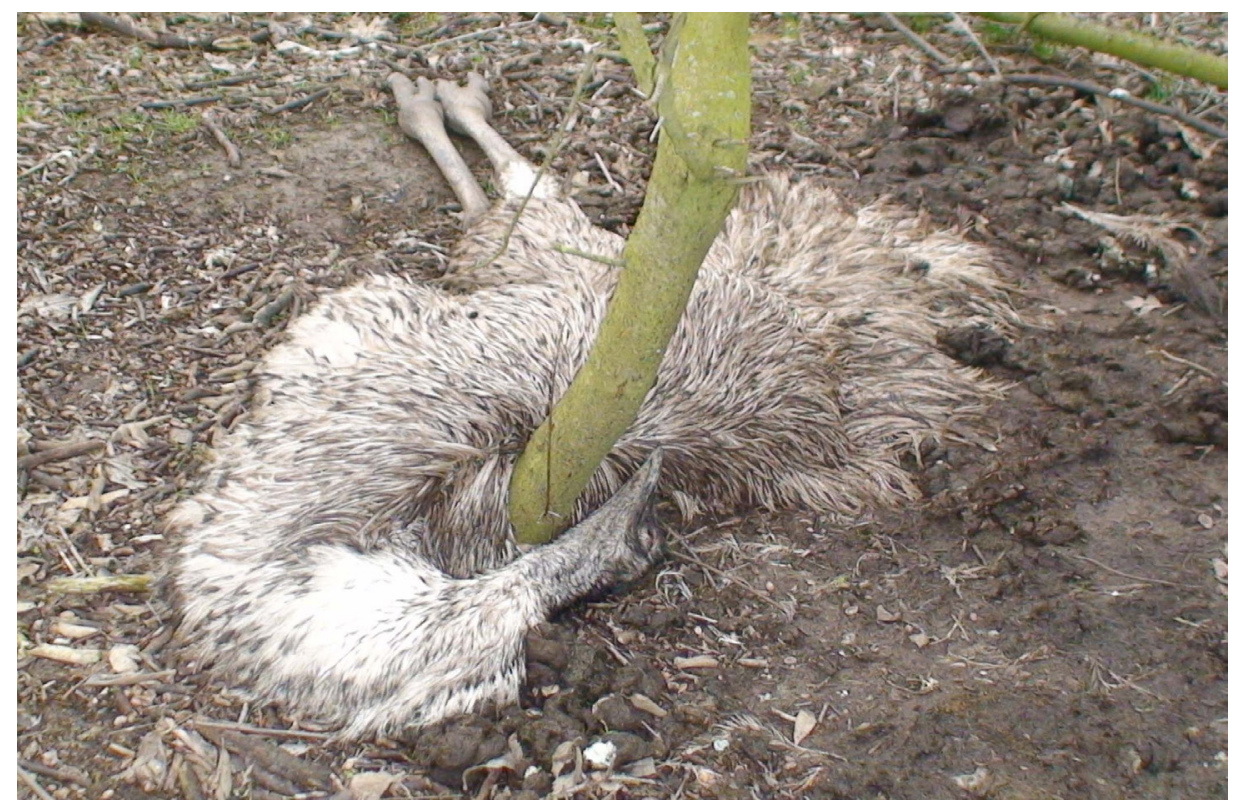

Figure 3: Dromaius novaehollandiae carrion

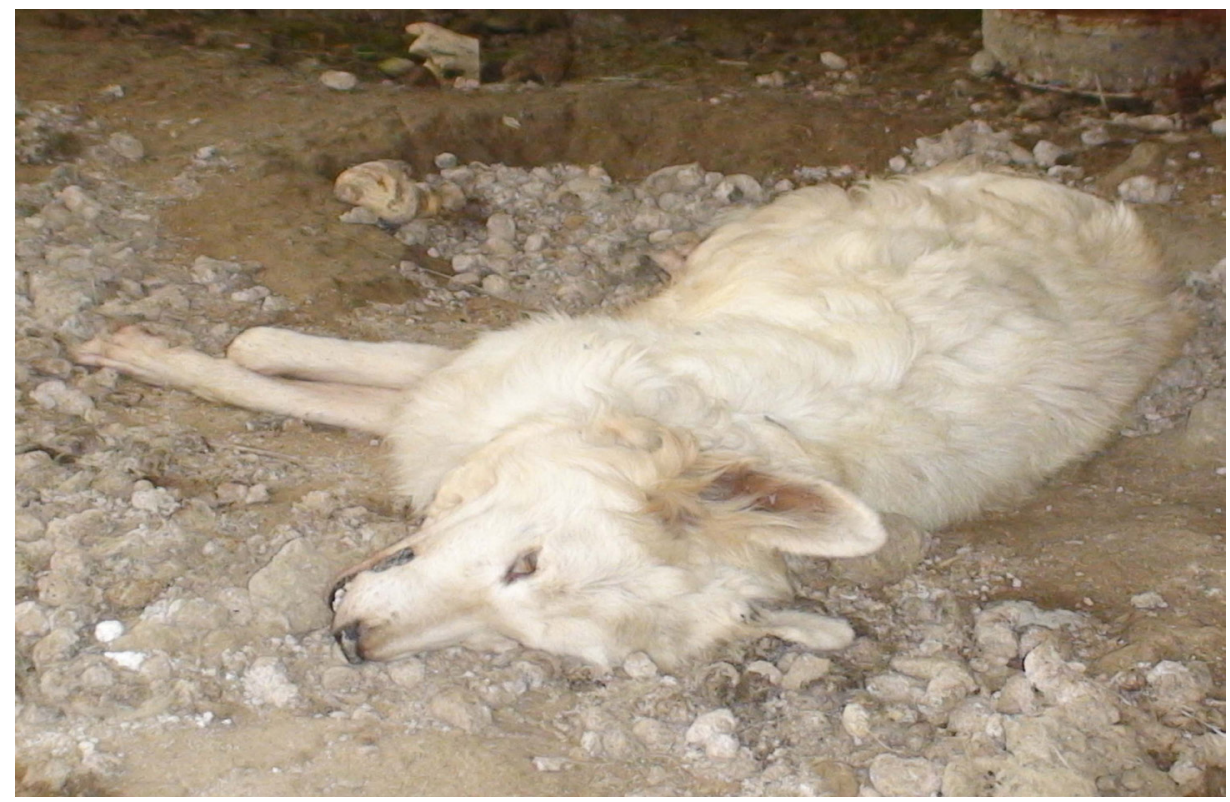

Figure 4: Carrion of Canis lupus familiaris

The insects sampled were: larval exuviae of Dermestidae (Dermestes maculatus) on the carcasses with the most advanced decomposition stages (on every Pot-bellied carrions, Dromaius novaehollandiae); on dog were collected only larvae of Calliphoridae (Calliphora vicina), and a carrion of sheep only larvae of Stratiomydae (Hermetia illucens). All adult and larval exuvie were isolated and stored in $80 \%$ ethanol, while larvae were reared in the laboratory to the adult emersion. The adults and larvae were identified using identification keys [9]. The Calliphora vicina and Hermetia illucens larvae collected on the carrions were removed and transferred into plastic jars $(10 \times 15 \times 22 \mathrm{~cm})$ covered with a gauze net. The bottom of each jar was covered with 3 -cm-thick sawdust, to provide a dry place for pupation. The jars were then placed into a precision environmental chamber (PIARDI_Mod. CC. 1500$)$ The temperature $\left(15^{\circ} \mathrm{C}\right)$, relative humidity $(70 \%)$ and fotoperiod $(14 \mathrm{~L} / 10 \mathrm{D})$ were strictly controlled and they were similar to typical weather conditions recorded at the crime scene. Observation of emerges occurred daily between 10 and 12 am. After adult emergence, the adult flies were killed, pinned and identified. For C.vicina and H. illucens we estimated the PMI (Post-mortem Interval) in accumulated degree days (ADD). Therefore, the time since oviposition or egg laying can be determined by careful examination of meteorological data, together with the identification of the species and stage of development of the insects associated with the remains. Unfortunately, the temperature of the scene of death was not recorded. Meteorological records were obtained from the local weather stations, located $15 \mathrm{Km}$ away, at Cocomaro di Cona (FE). Weather station indicated a mean temperature of $8.7-4.3^{\circ} \mathrm{C}$ over the previous two weeks, with mean precipitation of $10.1-16.6 \mathrm{~mm}$ [10-12]. 


\section{Results}

At the laboratory condition Calliphora vicina rhas requested 27 days from larva II instar to adult eclosion. So the oviposition would take place between 2 and March 3, 2010 day on which was performed the necropsy on the carcass. This result can not be real. Here is why, considering that from observations in the laboratory C.vicina is able to lay eggs only at a minimum temperature of $13{ }^{\circ} \mathrm{C}$, that the average ambient temperature at the crime scene was of $7-9^{\circ} \mathrm{C}$ except between $24-26$ February 2010 we have to change the date of oviposition, and indicate how minimum interval from death of the dog between 24-26 february 2010. Similar observations have been made for H.illucens larvae sampled on sheep carrion. The development threshold temperature, reported in literature [12], is of $10^{\circ} \mathrm{C}$; Lord and Pujol-Luz [14] reported that the larvae of $H$. illucens measure, to its full development, 20-32mm and that to reach this stage, to an average daily temperature of $27.8^{\circ} \mathrm{C}$, requires about 31 days $(861.8 \mathrm{ADD})$ we obtained a minimum interval from death between 01-15 October 2009. The appearance of Dermestes maculatus on decomposing remains of human and other animals makes it a candidate insect to estimate postmortem interval. This beetle can become one of the dominant insects present in mid to late decay and adults generally arrive 8 to 11 days following death $[15,16]$. Full development of Dermestes maculatus is only reached when temperatures are consistently above $18^{\circ} \mathrm{C}$, and will take 96 days at $18^{\circ} \mathrm{C}$ from the time the egg is laid to reach adulthood [17]. The optimum temperature for Dermestes maculatus development is approximately $30^{\circ} \mathrm{C}$, where the beetles reach adulthood around 38 days. No individuals completed development to the adult stage at 15 degrees [18]. It also was noted that this beetle was not present on pig carcasses during the winter or autumn season, but present during other seasons [19,20]. Since were sampled only the larval exuviae. Beetle exuviae are moderately tough, and may remain at a death scene long after the corpse has decomposed. In cases, like this, where remains are mummified, living dermestid adults and larvae may still be associated with the remains after a period of yars, also the mere presence of their larval remains is proof that dermestid beetles have fed extensively on the tissues [19]. In this case, we have considered that the entire development has been completed on the carcasses. Combining these factors the rate and the rate of decomposition we have established a PMI of 192-217 days (August 2009). In this study the entomological evidence has allowed to date the death of different animal carcasses and to establish that the first animal has died on August 2009 while the last one died during the second half of February 2010.

\section{Discussion}

The judicial authorities with also the entomological evidence has sentenced that because the farm was sold from June 2009 the new owner has likely abandoned all animals letting them to starve. In many cases when animal remains are discovered it is difficult or impossible to determine the time of death. Without this evidence, it is extremely difficult to pursue a case, so at the present time, many animal cruelty cases are not followed through, with the result that the culprits remains at large, and more animals are killed Once charged, a successful prosecution is dependent on strong physical evidence. Insects provide strong, defensible physical evidence which could be successfully used in court. In human cases, forensic entomology is usually of most value during the first few months after death. Years after death, it may be possible to determine season of death, based on species and numbers of insect remains present. In some respects, such evidence may be of more value in poaching cases or animal cruelty cases than in human cases, as season alone may not be enough in an old homicide case. This would mean that many more cases could be investigated than currently are pursued. The time of death also points the investigation into the correct time frame, which helps to focus the veterinary investigation and can be extremely important in the apprehension of a suspect.

\section{Conclusion}

This case highlights such as entomological survey become powerful evidence for the length of time of abuse or neglect, in court. Forensic practice applied to pets and wildlife is increasing in importance of and the veterinary profession has a key role to play [21]. There is a need to enhance the awareness of veterinarians, to introduce teaching and specialized training and provide access to information accordingly. Systems and protocols, some similar to those used in human forensic medicine, must be established and used. In this scenario the veterinary forensic entomology is not yet a recognized discipline but it is evolving rapidly. The forensic investigator indeed has often recognized the presence of entomological evidence in animal abuse or wildlife death investigations. Thus, application of quality assurance principles, could have a strategic role in enhancing trust among national veterinary services officials and consequently in facilitating the use of forensic entomology in veterinary medicine [22].

\section{Reference}

1. Anderson GS, Huitson NR (2004) Myiasis in pet animals in British Columbia: The potential of forensic entomology for determining duration of possible neglect. Can Vet J 45: 993-8

2. Hall RD (1990) Medicocriminal entomology. In: Catts EP, Haskell NH, editors. Entomology and death: a procedural guide. Clemson, SC: Joyce’s PrintShop 1-8.

3. Wall R, Warnes ML (1994) Responses of the sheep blowfly Lucilia sericata to carrion odour and carbon dioxide. Entomol Exp Appl 73: 239-46.

4. Anderson GS (2001) Succession on carrion and its relationship to determining time of death. In: Byrd JH, Castner JL, editors. Forensic entomology: the utility of arthropods in legal investigations. Boca Raton, FL: CRC Press 143-75.

5. Sharpe PJH, DeMichele DW (1977) Reaction kinetics of poikilotherm development. J Theor Biol 64: 649-70.

6. Greenberg B, Kunich JC (2002) Entomology and the law: flies as forensic indicators. Cambridge, U.K.: Cambridge University Press.

7. Ames C, Turner B (2003) Low temperature episodes in development of blowflies: implications for postmortem interval estimation. Med Vet Entomol 17: 178-86. 
8. Huffman EJ, Wallace JR (2012) Wildlife Forensics Methods and Apllications, Wiley-Blackwell 82-3.

9. Smith KGV (1986) A manual of forensic entomology. London, U.K.: British Museum of Natural History; Cornell University Press 1-205.

10. Anderson GS (1999) Wildlife Forensic Entomology: Determining Time of Death in Two Illegally Killed Black Bear Cubs. J Forensic Sci 44: 856-9.

11. Campbell A, Frazer BD, Gilbert N, Gutierrez AP, MacKauer M (1974) Temperature requirements of some aphids and their parasites. J Appl Ecol 11: 431-8.

12. May BM (1961) The occurrence in New Zealand and the life-history of the soldier fly Hermetia illucens (L.) (Diptera: Stratiomyidae). N Z J Sci 4: 55-65.

13. Higley LG, Haskell NH (2001) Insect development and forensic entomology. In: Byrd JH, Castner JL, editors. Forensic entomology: the utility of arthropods in legal investigations. Boca Raton, FL: CRC Press 418.

14. Lord WD, Goff ML, Adkins TR, Haskell NH (1994) The black soldier fly Hermetia illucens (Diptera, Stratiomyidae) as a potential measure of human postmortem interval: observations and case histories. J Forensic Sci 39: 215-22.

15. Charabidze D, Colard T, Benoit V, Pasquerault T, Hedouin V (2013) Involvement of larder beetles (Coleoptera: Dermestidae) on human cadavers: a review of 81 forensic cases Int J Legal Med 128: 1021-30.

16. Prado e Castro C, Garcia MD, Martins da Silva P, Faria e Silva I, Serrano A (2013) Coleoptera of forensic interest: A study of seasonal community composition and succession in Lisbon, Portugal. Forensic Sci Int 232: 73-83.

17. Arnaldos MI, Sanchez F, Alvarez P, Garcia MD (2004) A forensic entomology case from the southeastern Iberian Peninsula. Aggrawal's Internet J Forensic Med Toxicol 5: 22-5.

18. Richardson MS, Goff ML (2001) Effects of temperature and intraspecific interaction on the development of Dermestes maculatus (Coleoptera: Dermestidae). J Med Entomol 38: 347-51.

19. Byrd JH, Castner J (2001) Insect of Forensic Importance. In: Byrd JH, Castner JL, editors. Forensic entomology: the utility of arthropods in legal investigations. Boca Raton, FL: CRC Press 418.

20. Wang J, Li Z, Chen Y, Chen Q, Yin X (2008) The succession and development of insects on pig carcasses and their significances in estimating PMI in south China. Forensic Sci Int 179: 11-8.

21. Bhat MA, Shrivastav AB, Qureshi SR, Quadri SA (2011) Forensic exploitation of Veterinary Entomology. IJAVMS 5: $429-37$.

22. Gaudry E, Dourel L (2013) Forensic entomology: implementing quality assurance for expertise work. Int J Legal Med 127: $1031-7$.

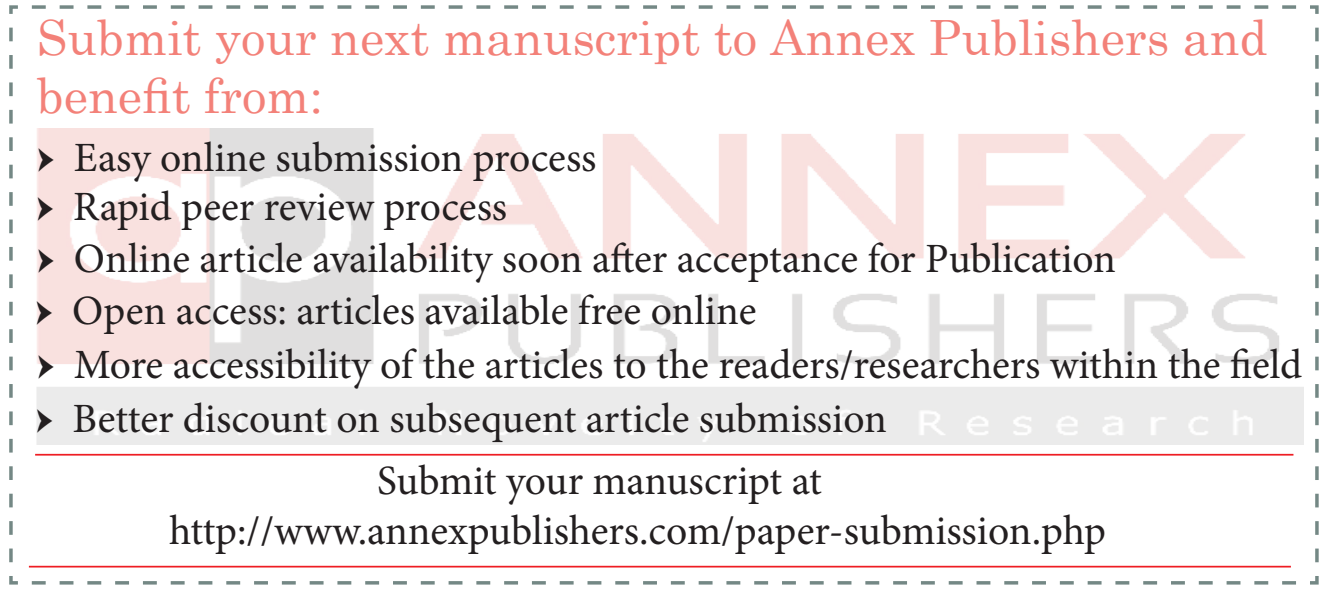

